Branch"@2020.

Available online

\title{
HOBBIES AND EXTRACURRICULAR ACTIVITIES PRACTICED AMONG DENTISTS AND MEDICAL PRACTITIONERS IN CHENNAI - A CROSS-SECTIONAL STUDY
}

\author{
Dr.Sanjana.S, Dr Rachel Chacko, Dr Parameswaran.T.M,
} Private Practitioners, Chennai, Tamilnadu, India

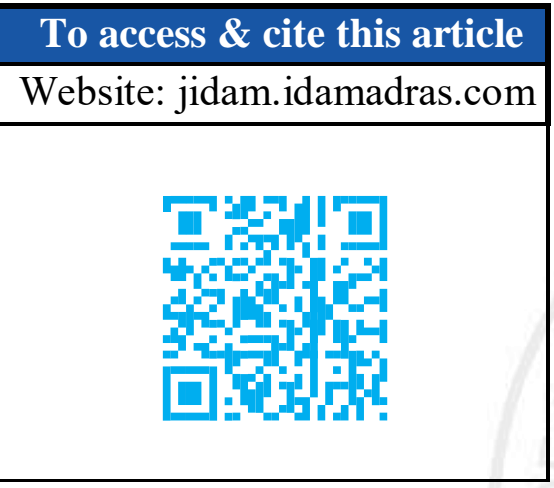

DOI:10.37841/jidam_2020_V7_I3_02

\section{Address for Correspondence:}

Dr.Sanjana.S, MDS, Private Practitioner, Chennai-600089, Tamilnadu, India Email id: sanjanachopra003@gmail.com

$\begin{array}{ll}\text { Received } & : 07.09 .2020 \\ \text { Accepted } & : 17.09 .2020 \\ \text { Published } & : 27.09 .2020\end{array}$

\begin{abstract}
BACKGROUND: Hobbies and Extracurricular Activities (EA) provide an outlet for stress. The Medical and Dental field is a long emotionally taxing journey. Stress progressively develops over the course of Medical/Dental education. It is challenging to strike a balance between leading a successful medical profession as well as pursuing their favored Hobbies/EA's.
\end{abstract}

AIMS AND OBJECTIVES: 1.Evaluate the number of dental and medical practitioners participating in hobbies and extracurricular activities. 2) To correlate the involvement of extracurricular activity in terms of progress, joyfulness and level of achievement. 3) To suggest a schedule to continue long lost hobbies and extracurricular activities.

MATERIALS AND METHODS: A cross-sectional study was carried out amongst the dental and medical practitioners in Chennai between March 2017 and May 2017. A total of 120 self-administered questionnaires were distributed amongst dentists working at 2 private colleges and as dental and medical practitioners in private clinics. The questionnaire contained demographic details along with a set of 14 questions which included 6 openended questions and 8 closed-ended questions.

RESULTS: Upon evaluating the number of people involving in extracurricular activities, it was found significant that doctors working more than 5 hours could not continue their activities regularly and those whom worked less than 5 hours a day were able to involve regularly. Around 13 people did not answer those two questionnaires. The correlation coefficient was positively correlated 0.012 which showed a weak positive correlation proving that the dentists who balanced between profession and extracurricular activities outperform the people who did not take part in extracurricular activities. This study showed that working less or more has a significant impact the extracurricular activities to a negative correlation. (0.047).

CONCLUSION: Involvement by the dentists and medical practitioners in hobbies and extracurricular activities and it was found significant that,

- Majority of them who engaged in activities were continuing them regularly.

- They also wished to reschedule their time to participate effectively in hobbies and activities.

KEY WORDS: Hobbies, Extracurricular activities, Stress, Dental professional / medical professional. 


\section{INTRODUCTION:}

Dentists and Medical practitioners generally lead a stressful lifestyle that hinders them from pursuing their hobbies and extra-curricular activities ${ }^{1,2}$. Extracurricular activities (EA) are those that fall outside the realm of the medicinal/ one's profession. They commonly include singing, dancing, sports, gym etc. Hobby can be termed as an activity of interest, or passion that is carried out during one's own time for pleasure or relaxation. It comprises of reading books, travelling, gardening among other things.

Hobbies and Extracurricular activities provide an outlet for stress and help in prevention of burnout. It occurs by shifting focus towards a nonwork-related task and diverting our mind to focus on something else. Literature suggests that being engaged in such activities has attributed to a healthier lifestyle by preventing major health risks and a balance between work and personal life ${ }^{3}$. Engaging in these activities also correlated to higher levels of positive psychosocial states and lower levels of depression and negative effect ${ }^{4,5}$.

Stress develops progressively during the course of medical/dental education. In the course of both pre-clinical and clinical years, medical and dental students are expected to take responsibilities of patients and simultaneously learn a vast amount of facts and concepts with a limited amount of time which creates a hectic environment for them. Studies have shown that preclinical years are less stressful than clinical years and additionally relationships with staff are considered more stressful than treatment of patients $s^{6,7,8}$. Maintaining a well-balanced career and EA will add to their public image and prestige in their social life. Although these activities may contribute to student satisfaction and reduce stress levels, if not properly balanced can burden academic routine by overlapping class schedules and also reduce time for other essential activities during weekends ${ }^{9}$. Hence, medical and dental practitioners should try to engage themselves in different hobbies/extracurricular activities to cope with this demanding environment. These activities can alleviate anxiety, stress, and produce positive effects on mental and physical health. In many instances, patients change doctors not because of poor diagnostic or surgical skills, but because of poor communication. There is a serious lack of doctor's compassion, care and interest which relieve patient's from their distress and concerns as doctors themselves carry a burden called stress ${ }^{10}$.

The number of studies tackling stress by participating in EA and hobbies amongst dentists and medical practitioners has been on the rise in the past few years ${ }^{11}$. However, most have focused on the students and not the practitioners. Furthermore, there are no studies that focus on the link between the participation in EA and hobbies and relief of stress and depression levels amongst them. This study aims at 1) evaluating the number of dental and medical practitioners participating in hobbies and extracurricular activities. 2) To correlate the involvement of extracurricular activity in terms of progress, joyfulness and level of achievement. 3) To suggest a schedule to continue long lost hobbies and extracurricular activities.

\section{MATERIALS AND METHODS:}

A cross-sectional study was carried out amongst the dental and medical practitioners in Chennai between March 2017 and May 2017. Dentists from two private colleges, dental and medical practitioners in private clinics in Perambur were evaluated. The area Perambur was randomly selected from the list of areas falling within the Chennai Corporation Limit. By convenience sampling method the participants from Perambur were selected. The questionnaire was given to all those present on the day of evaluation. Informed consent was obtained prior to distribution of the questionnaire. The questionnaire was calibrated by giving it to a sample of 10 subjects as a part of the pilot study. It was checked for consistency in answering the closed-ended questionnaire and homogenicity was obtained for the open-ended questions so that it can be evaluated effectively.

A total of 120 self-administered questionnaires were distributed based on previous study $^{12}$ using Gpower Software (Power-80\%). The questionnaire which had demographic data to be filled along with a set of 14 questions which was given to the dentists and medical practitioners. The questionnaire included 6 open-ended questions and 8 closed-end questions. The 6 open-ended questionnaires provided elaborate details of the extracurricular activities and hobbies. Correlates of hobbies with any award or certificates 
or its relation with any achievement was quantified using a chi-squared test at a significance of $\mathrm{P}<0.05$.

\section{RESULTS:}

TABLE 1 (Evaluation of the significance between people involving in extracurricular activities and those continuing them regularly) Pearson's Chi-squared value (42.259), Degree of freedom (6) and $\mathrm{P}$ value (0.00)- Significant

\section{INVOLVEMENT IN EXTRACURRICULAR ACTIVITIES}

\begin{tabular}{|l|l|l|}
\hline CONTINUING & YES & NO \\
\hline YES & 43 & 26 \\
\hline NO & 5 & 32 \\
\hline
\end{tabular}

Upon evaluating the amount of people involving in extracurricular activities, it was found significant that most of them are continuing them regularly. Around 14 people did not answer those two questionnaires.

TABLE 2 (Evaluation of significance between people who continue regularly and wanting to reschedule their time)

Pearson's Chi-squared value (23.237), Degree of freedom (4) and P value (0.00)- Significant

\section{CONTINUING REGULARLY}

\begin{tabular}{|c|c|c|}
\hline $\begin{array}{c}\text { WISH TO } \\
\text { RESCHEDULE }\end{array}$ & YES & NO \\
\hline YES & 20 & 13 \\
\hline NO & 42 & 15 \\
\hline
\end{tabular}

Upon evaluating the amount of people continuing them regularly, it was found significant that most of them wished to reschedule their time in involving in their activities. Around 30 people (25\%) did not answer those two questionnaires.

TABLE 3 (Evaluation of significance between the working hours of the people and those continuing to participate regularly)

Pearson's Chi-squared value(1.925), Degree of freedom (4) and P value (0.750) - Not Significant.
HOURS OF WORK

\begin{tabular}{|c|c|c|c|}
\hline $\begin{array}{c}\text { CONTINUING } \\
\text { REGULARLY }\end{array}$ & 5 & $5-10$ & $>10$ \\
\hline YES & 6 & 30 & 12 \\
\hline NO & 12 & 33 & 14 \\
\hline
\end{tabular}

Upon evaluating the number of hours they work in a day, it was found significant that those working more than 5 hours could not continue their activities regularly and those whom worked less than 5 hours a day were able to involve regularly. Around 13 people did not answer those two questionnaires.

TABLE 4 (Correlation between the number of years in the dental profession with extracurricular activities pursued regularly)

\begin{tabular}{|c|l|l|}
\hline $\begin{array}{c}\text { NUMBER OF } \\
\text { YEARS IN } \\
\text { DENTAL } \\
\text { PROFESSION }\end{array}$ & $\begin{array}{c}\text { EXTRACURRICULAR } \\
\text { ACTIITIES PURSUED } \\
\text { YES/ } \\
\text { NO }\end{array}$ & $\begin{array}{l}\text { CORRELATION } \\
\text { COEFFICIENT }\end{array}$ \\
\hline <5Years & 19 & \multirow{2}{*}{0.012} \\
\hline $5-10$ Years & 30 & \\
\hline 10 Years & 13 & \\
& 20 & \\
& 16 & \\
\hline
\end{tabular}

Upon correlating the number of years in the dental profession with extracurricular activities pursued regularly using Pearson's correlation. It was found that majority of the dental professionals have opted NO. The number of dental professionals who prefer to take part in other extracurricular activities are 48 individuals out of 120 individuals. The people who followed their passion were majorly in the group of 5-10years nearly 20 individuals out of 48 
positive response. The correlation coefficient was positively correlated 0.012 which showed a weak positive correlation proving that the dentists who balanced between profession and extracurricular activities outperform the people who did not take part in extracurricular activities.

TABLE 5 (Correlation of duration of work hours per day with involvement in extracurricular activities)

\begin{tabular}{|l|l|l|l|}
\hline $\begin{array}{c}\text { NUMBER OF } \\
\begin{array}{c}\text { HOURS OF } \\
\text { WORK } \\
\text { EXPOSURE }\end{array}\end{array}$ & \multicolumn{2}{|c|}{$\begin{array}{c}\text { EXTRACURRICULAR } \\
\text { ACTIVIES PURSUED }\end{array}$} & $\begin{array}{l}\text { CORRE } \\
\text { LATION } \\
\text { COEFFI } \\
\text { CIENT }\end{array}$ \\
\cline { 2 - 3 } & YES & NO & \\
\hline$<5$ Hours & 9 & 13 & \\
\hline $5-10$ Hours & 43 & 25 & \multirow{2}{*}{-0.047} \\
\hline$>10$ Hours & 18 & 11 & \\
\hline
\end{tabular}

Upon correlating using Pearson's correlation test, the duration of work hours per day with involvement in extracurricular activities, the number of people who answered positively are 48 individuals. Out of these 30 individuals belonged to the 5-10years group. This shows that working less or more has a significant impact the extracurricular activities to a negative correlation. $(-0.047)$

\section{DISCUSSION:}

In the current scenario, it's difficult to strike a balance between leading a successful medical profession as well as pursuing their favoured hobbies/ EA's. This is seen by the declining trend of medical practitioners who drop their hobbies to maintain a full-fledged profession centric lifestyle ${ }^{3}$.

Stress develops at a very early stage from the beginning of medical or dental profession as a student. Hence our study is mainly compared with the stress level and importance of hobbies and extracurricular activities amongst dental and medical students which eventually would have led to a monotonous lifestyle even after becoming practitioner. In a study which evaluated the stress level amongst students in medical college, it was found that the majority $(62.3 \%)$ of students had high levels of cynicism $(n=155)$ and $58.6 \%$ had high levels of emotional exhaustion $(\mathrm{n}=146)$, and $60.2 \%$ had low levels of professional efficacy $(n=150)^{5}$. Heath JR et al in their study found that there was high stress level among Malaysian dental students due to the fear of failure in a course ranking as the top stressor and the demands of the course reflected on the lack of time for relaxation and reduced holidays, particularly amongst the third and the fourth years students, respectively ${ }^{13}$.

As this study aimed at inculcating the importance of the practice of hobbies and extracurricular activities amidst the stressful life lead by the dentists and medical practitioners today, it was found that professionals who had been working for more than 5-10 years in their field for more than 5 hours a day failed to involve themselves into any type of hobby or extracurricular activity. Whereas people working less than 5 hours a day had more amount of involvement in extracurricular activities like Sports and Arts.

Mostly students get engaged in EAs to shape personality and develop transferable skills, whereas other may have more strategic purposes to flourish resumes ${ }^{11}$. Upon asking them whether they were continuing their activities regularly despite their stressful professional life, the results were found that many were unable to continue them on a regular basis giving time constraints as the main reason.

An interesting finding of this study revealed that although time constraints was enlisted as the main factorial for compromising in their participation in hobbies and extracurricular activities, many were concerned in rescheduling their time to change their lifestyle which would give them a better opportunity to involve themselves more in activities and hobbies. In another study it was proved that older doctors have lower levels of burnout and psychological distress than younger doctors as years of practice generally lead to increased confidence in the role of doctor with greater life experience and clinical wisdom that brought a good doctor- patient relationship ${ }^{14}$. 
As already mentioned that hobbies are different from extracurricular activities, quite a number of dentists and medical practitioners enlisted 'listening to music, travelling and reading books' as their main hobbies in their past-time for pleasure and relaxation. The study also revealed that majority didn't want to seek new hobbies even if they didn't have any. Music related activities and physical activities had better burnout outcomes by reducing anxiety, depression and perceived stress in Jawad Fares' study ${ }^{16}$.

Frustration being the main drawback which one gets when he/she is leading a stressful life, engaging in hobbies and extracurricular activities has significantly seen to reduce their stress and depression level. In Lionelle et al's study ${ }^{16}$, about $50.2 \%$ of health care professionals reported having some health problem the most commonly reported were; headaches $(16.9 \%)$, anxiety $(15.8 \%)$, hypertension $(15.6 \%)$ and problems in the lumbar spine (14.0\%). In this study, majority of them have responded saying participation in hobbies and extracurricular activities lowered their frustration level drastically and that they feel exuberant while pursuing them.

- Furthermore, this study disclosed that a lot of dentists and medical practitioners have attended competitions related to their hobbies and extracurricular activities.

- This study high-lighted mainly on the involvement by the dentists and medical practitioners in hobbies and extracurricular activities and it was found significant that,

- Majority of them who engaged in activities were continuing them regularly.

- They also wished to reschedule their time to participate effectively in hobbies and activities.

\section{CONCLUSION:}

This novel study thus concludes that the percentage of dentists and medical practitioners who engaged themselves in hobbies and extracurricular activities are indubitably high. Whilst there are many research studies being published based on the stress levels amongst medical students, there is no literature published equally in comparison to this study which unveiled the importance of seeking hobbies and other activities amongst dental and medical practitioners. Additionally, "Hobby Hour" could be embedded in the dental and medical curriculum so that students will have continued practice of their activities at their college level itself, which might have a better impact on their continuation even in their professional life. Thus this study clearly highlights the profound benefits of practicing hobbies and extracurricular activities and its beneficial impacts on dentist's and medical practitioner's lifestyle to overcome stress and pressure.

\section{ACKNOWLEDGEMENT:}

- We would like to thank all the practitioners who participated in the study

\section{FINANCIAL SUPPORT AND SPONSORSHIP:}

\section{Nil}

\section{CONFLICTS OF INTEREST:}

There are no conflicts of interest.

\section{REFERENCES:}

1. More than half of dentists say stress is affecting their practice. Br Dent J. 2019 Jan $11 ; 226(1): 7$.

2. Willcock SM, Daly MG, Tennant CC, Allard BJ. Burnout and psychiatric morbidity in new medical graduates. Med J Aust [Internet]. 2004 Oct 4 [cited 2020 Jul 1];181(7):357-60.

3. Jenkins S, Johnson I, Ginley J. Work, Stress and Play: Students' perceptions of factors impacting on their studies and well-being. Eur J Dent Educ [Internet]. 2019 Aug 1 [cited 2020 Jul 1];23(3):349-54.

4. Pressman SD, Matthews KA, Cohen S, Martire LM, Scheier M, Baum A, et al. Association of enjoyable leisure activities with psychological and physical well-being. Psychosom Med [Internet]. 2009 [cited 2020 Jul 1];71(7):725-32. 
5. Almalki SA, Almojali AI, Alothman AS, Masuadi EM, Alaqeel MK. Burnout and its association with extracurricular activities among medical students in Saudi Arabia. Int J Med Educ [Internet]. 2017 Apr 26 [cited $2020 \mathrm{Jul} 1] ; 8: 144-50$.

6. Tedesco L. A psychosocial perspective on the dental educational experience and student performance. J Dent Educ [Internet]. 1986 Oct 1 [cited 2020 Jun 29];50(10):601-5.

7. Tangade PS, Mathur A, Gupta R, Chaudhary S. Assessment of Stress Level among Dental School Students: An Indian Outlook. Dent Res J (Isfahan) [Internet]. 2011 [cited 2020 Jun 29];8(2):95-101.

8. Grandy T, Westerman G, Combs C, Turner C. Perceptions of stress among third-year dental students. J Dent Educ [Internet]. 1989 Dec 1 [cited 2020 Jul 1];53(12):718-21.

9. Ferreira IG, Carreira LB, Murphy N, Soares ACB, Fonseca PCC, Sousa LEA de. Extracurricular activities: a comparative perspective among health colleges in Brazil and Ireland. ABCS Heal Sci. 2018 Aug $2 ; 43(2)$.

10. Ayoub F, Fares Y, Fares J. The psychological attitude of patients toward health practitioners in Lebanon. N Am J Med Sci [Internet]. 2015 Oct 30 [cited 2020 Jul 1];7(10):452.

11. Almasry M, Kayali Z, Alsaad R, Alhayaza G, Ahmad MS, Obeidat A, et al. Perceptions of preclinical medical students towards extracurricular activities. Int $\mathrm{J}$ Med Educ [Internet]. 2017 Aug 16 [cited 2020 Jul 1];8:285-9.
12. Doshi D, Jain A, Vinaya K, Kotian S. Quality of life among dentists in teaching hospitals in South Canara, India. Indian J Dent Res. 2011;22(4):552-5.

13. Heath JR, Macfarlane $\mathrm{T}$ V., Umar MS. Perceived sources of stress in dentalstudents. Dent Update [Internet]. 1999 [cited 2020 Jul 1];26(3).

14. Peisah C, Latif E, Wilhelm K, Williams B. Secrets to psychological success: Why older doctors might have lower psychological distress and burnout than younger doctors. Aging Ment Heal [Internet]. 2009 Mar [cited 2020 Jul 1];13(2):300-7.

15. Fares J, Saadeddin Z, Al Tabosh H, Aridi $\mathrm{H}$, El Mouhayyar C, Koleilat MK, et al. Extracurricular activities associated with stress and burnout in preclinical medical students. J Epidemiol Glob Health [Internet]. 2016 Sep 1 [cited 2020 Jul 1];6(3):177-85.

16. Leonelli LB, Andreoni S, Martins P, Kozasa EH, De Salvo VL, Sopezki D, et al. Estresse percebido em profissionais da estratégia saúde da família. Rev Bras Epidemiol [Internet]. 2017 20(2):286-98. 